\title{
The prevalence and associated cardiovascular risk factors in resistant hypertensive subjects in Eastern India
}

\author{
Pijush Kanti Mandal', Arpan Kumar Dey², Subhraprakash Pramanik², Shovan Kumar Das ${ }^{3}$, Sumit Khotick, \\ Avik Das $^{4}$, Sattyendra Nath Dutta ${ }^{5}$, Amit Sarkar6, Somnath Dasgupta ${ }^{7}$ \\ ${ }^{1}$ Senior Resident-Medicine, ESI PGIMSR, Maniktala, Kolkata, India, 2,4,6,7 Senior Resident, Post-Graduate Trainee, RMO-CT, Professor and \\ $H O D$, Medicine, Burdwan Medical College and Hospital, Burdwan, India, ${ }^{3}$ Medical Officer, Ghatal SDH, Purba Midnapore, India, ${ }^{5}$ Post-Graduate \\ Trainee, Medicine, Medical College, Kolkata, India
}

\section{A B S TR A C T}

Background: To study the prevalence and associated cardiovascular risk factors in resistant hypertensive subjects among hypertensives. Methods: A descriptive cross-sectional observational study was carried out among 300 hypertensive patients attending 'Hypertension Clinic' and providing informed written consent from October 2013 to December 2013 at Burdwan Medical College and Hospital, Burdwan, West Bengal in India. A pre-tested interviewer-administered questionnaire was used for data collection. Chi-squire test and odds ratio were calculated using biomedical software. The study was approved by Ethics Review Committee of our Institution. Results: The prevalence of resistant hypertension was $23.33 \%$ among all hypertensives. The patients with Resistant hypertension were significantly associated with older age groups ( $>55$ years) $(77.1 \%$ vs. $38.3 \%$, p value $<0.001$, OR 5.446 , $95 \% \mathrm{Cl} 2.935$ and 10.104$)$, Obesity $\left(\mathrm{BMI}>27.5 \mathrm{~kg} / \mathrm{m}^{2}\right)(67.1 \%$ vs. $45.7 \%, \mathrm{p}$ value 0.002 , OR $2.433,95 \% \mathrm{Cl} 1.387$ and 4.268$)$, Diabetes mellitus $(72.9 \%$ vs. $45.2 \%$, p value $<0.001$, OR $3.252,95 \% \mathrm{Cl} 1.808$ and 5.851 ), Prolonged hypertension ( $>10$ years; $74.3 \%$ vs. $43.9 \%$, $\mathrm{p}$ value $<0.001$, OR 3.690, $95 \% \mathrm{Cl} 2.033$ and 6.696) and co-morbidity like Ischemic Heart Disease $(60 \%$ vs. $44.8 \%$, p value 0.026 , OR $1.850,95 \% \mathrm{Cl} 1.073$ and 3.187 ) as risk factors as compared to patients with non-resistant hypertension. Conclusions: Nearly one fourth of the hypertensive persons were suffering from resistant hypertension, which was significantly associated with the presence of older age, obesity, diabetes mellitus, longer duration of hypertension and co-morbidity like Ischemic Heart Disease as risk factors.
Access this article online

Website:

http://nepjol.info/index.php/AJMS

Key words: Resistant hypertension, Prevalence, Risk factors, Eastern India

\section{INTRODUCTION}

Majority of patients $(>90 \%)$ with hypertension suffer from essential or primary hypertension, while the remaining minority have secondary hypertension. It is estimated that only one-third of patients on treatment have their blood pressures well controlled. ${ }^{1}$ A considerable percentage of poorly control falls into a category known as 'resistant hypertension' of which pathophysiology and risk factors are not fully understood. ${ }^{2}$ Resistant hypertension is defined as "Suboptimal control of blood pressure despite using three antihypertensive agents inclusive of a diuretic, and patients who need $\geq 4$ drugs to control blood pressure". ${ }^{2}$ Despite having guidelines on management of resistant hypertension, it has become a problem to control blood pressure up to recommended levels, possibly due to poor understanding of pathophysiology and risk factors. Studies have shown that older age, obesity, excessive use of alcohol, and high sodium intake are strongly correlated with poor control of hypertension. ${ }^{3,4}$ Patient factors such as compliance and knowledge, and healthcare system factors like limitation of resources and lack of reminders of appointments also plays a major role in poor blood pressure control..$^{5-9}$ Managing resistant hypertension is difficult and they are more likely to have target organ damage and have higher cardiovascular risks than patients with well controlled blood pressure. ${ }^{10}$ The prevalence rate for hypertension in urban India is $29-45 \%$ in men and $25-38 \%$ in women, while data from other South Asian countries are sparse. ${ }^{11,12}$ The present 
study aims to study the prevalence of 'Resistant' hypertension in hypertensive population of South Asian origin and define deferential risk factors in the same population.

\section{MATERIALS AND METHODS}

In this hospital based observational descriptive cross sectional study, we included 300 hypertensive patients attending our "Hypertension Clinic" over a period of 3 months from October 2013 to December 2013 using a random sampling technique. Ethical approval for the study was obtained from the Ethics Review Committee of our Institution. Patients who gave the informed written consent were included in the study. The patients who visited the clinic for the 1 st time, patients who were too ill/unable to answer the questionnaire and patients who did not consent were excluded from the study.

A pre-tested expert-validated interviewer administered questionnaire was used for data collection. The following data were collected; socio-demographic details, duration of disease, medication history, risk factors, complications and other co morbidities. The following risk factors were evaluated; history of smoking, alcohol consumption, drugs (Non-Steroidal Anti-Inflammatory Drugs, Steroids and Oral Contraceptive Pills), family history, high salt intake and presence of obesity. The antihypertensive drugs currently used by the patients were recorded according to their classes and drugs used for other co-morbidities were also documented. Patients' compliance to treatment was also evaluated. Body Mass Index (BMI) was calculated as weight in kilograms divided by height squared in meters $\left(\mathrm{kg} / \mathrm{m}^{2}\right)$. Two consecutive resting seated blood pressures were recorded 10 minutes apart, manually using mercury sphygmomanometers. Patients' previous 3 blood pressure values were taken from their medical records in clinic books.

Resistant hypertension was defined as "Suboptimal blood pressure despite using three antihypertensive agents inclusive of a diuretic, and patients who need 4 or more drugs to control blood pressure". ${ }^{2}$ Hypertension treatment targets were $<140 / 90 \mathrm{mmHg}$ for patients without any co-morbidities and $<130 / 90 \mathrm{mmHg}$ for patients with diabetes mellitus and renal disease. ${ }^{13}$ Obesity was defined as BMI $\geq 27.5 \mathrm{~kg} / \mathrm{m} 2$, based on WHO criteria for Asians. ${ }^{14}$ High salt intake was defined as an intake of sodium $>3 \mathrm{mg} /$ day based on Food Frequency Questionnaires. Current cigarette smokers were defined as adults aged $\geq 18$ years who reported having smoked $\geq 100$ cigarettes during their lifetime and who now smoke every day or some days. ${ }^{15,22}$ Current alcohol consumption was defined as $\geq 1$ alcoholic drink per month. ${ }^{16}$ Presence of diabetes mellitus, ischaemic heart disease, chronic kidney disease and dyslipidaemia were confirmed according to standard definition.
Data were analysed using Statistical Package for the Social Sciences (SPSS) version 20 for Windows. The non-parametric data was tested using chi-squire test and relative risk were estimated in all patients with 'presence of Resistant hypertension (RHT)' with co-variants like older age ( $>55$ years), gender, duration of hypertension ( $>10$ years), current cigarette smoking, current alcohol consumption, high salt intake, diabetes mellitus, ischaemic heart disease, dyslipidaemia, chronic kidney disease and obesity $\left(B M I>27 \mathrm{~kg} / \mathrm{m}^{2}\right)$ as the independent variables. A P value $<0.05$ was considered statistically significant.

\section{RESULTS}

In our study, among 300 hypertensive patients, 70 (23.33\%) were identified as resistant hypertensive and rest 230 (76.66\%) are non-resistant hypertensive patients (Figure 1). Patients of older age group ( $>55$ years) were $142(47.3 \%)$, and male and female were 55\% (165) and 45\% (135) respectively. Family history of cardio-vascular disease was present in $40 \%$ (120). High amount of salt intake was noted in $25.7 \%$ (77) patients. In $50.7 \%$ (152) hypertensive patients obesity (BMI $\left.>27 \mathrm{~kg} / \mathrm{m}^{2}\right)$ was associated. $14.3 \%$ (43) hypertensive patients were smoker and $12 \%$ (36) were alcoholic. Diabetes mellitus was associated in 51.7\% (155). Prolonged hypertension ( $>10$ years) was present among $51 \%$ (153). Dyslipidaemia was present in 57.7\% (173) and co-morbid conditions like Ischemic Heart Disease and Chronic Kidney Disease was associated in 48.3\% (145) and $12 \%$ (36) of patients respectively (see Table 1).

Gender-wise distribution of resistant hypertension, other cardio-vascular risk factors and co-morbidities revealed no significant difference except smoking and alcohol consumption that were more prevalent among males which can be explained by local cultural trends in this area (see Table 2).

The patients with resistant hypertension were significantly associated with older age groups ( $>55$ years) $(77.1 \%$ vs. $38.3 \%$, p value $<0.001$, OR $5.446,95 \%$ CI 2.935 and 10.104$)$, Obesity $(\mathrm{BMI}>27.5 \mathrm{~kg} / \mathrm{m} 2)(67.1 \%$ vs. $45.7 \%$, p value 0.002 , OR $2.433,95 \%$ CI 1.387 and 4.268$)$, Diabetes mellitus (72.9\% vs. $45.2 \%$, p value $<0.001$, OR 3.252, 95\% CI 1.808 and 5.851), Prolonged hypertension ( $>10$ years) $(74.3 \%$ vs. $43.9 \%$, p value $<0.001$, OR 3.690, 95\% CI 2.033 and 6.696) and co-morbidity like Ischemic Heart Disease ( $60 \%$ vs. $44.8 \%$, p value 0.026 , OR $1.850,95 \% \mathrm{CI} 1.073$ and 3.187 ) as risk factors as compared to patients with non-resistant hypertension (see Table 3).

\section{DISCUSSION}

Majority of patients in both resistant (67.1\%) and nonresistant $(45.7 \%)$ hypertension groups were obese. Obesity 


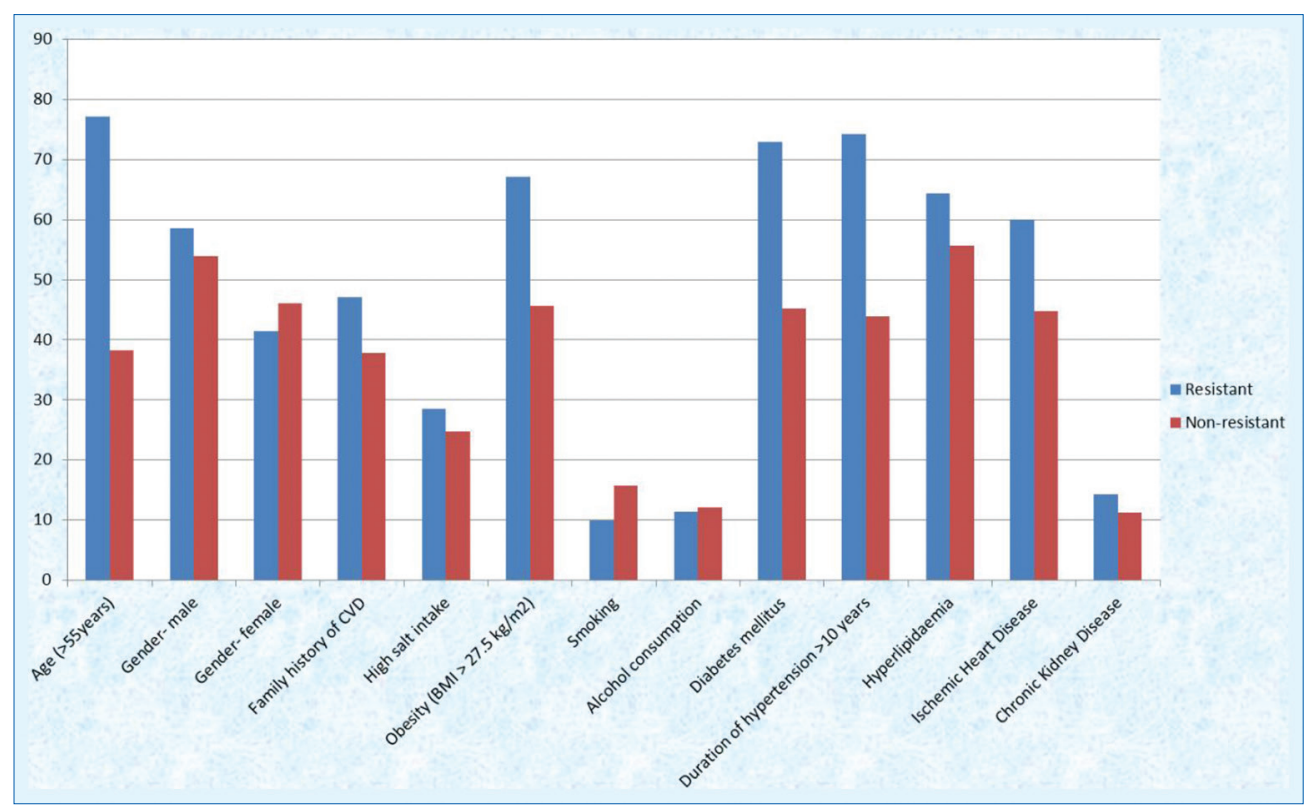

Figure 1. The diagram showing different risk parameters in 'Resistant' and 'non-resistant' hypertensive patients

\begin{tabular}{|c|c|c|c|c|}
\hline Parameters & All patients & Resistant & Non-resistant & $P$ value \\
\hline Age (>55 years) & $142(47.3 \%)$ & $54(77.1 \%)$ & $88(38.3 \%)$ & $<0.001$ \\
\hline Male & $165(55 \%)$ & $41(58.6 \%)$ & $124(53.9 \%)$ & 0.493 \\
\hline Female & $135(45 \%)$ & $29(41.4 \%)$ & $106(46.1 \%)$ & 0.493 \\
\hline Family history of CVD & $120(40 \%)$ & $33(47.1 \%)$ & $87(37.8 \%)$ & 0.164 \\
\hline High salt intake & $77(25.7 \%)$ & $20(28.6 \%)$ & $57(24.8 \%)$ & 0.525 \\
\hline Obesity $\left(\mathrm{BMI}>27.5 \mathrm{~kg} / \mathrm{m}^{2}\right)$ & $152(50.7 \%)$ & $47(67.1 \%)$ & $105(45.7 \%)$ & 0.002 \\
\hline Smoking & $43(14.3 \%)$ & $7(10 \%)$ & $36(15.7 \%)$ & 0.237 \\
\hline Alcohol consumption & $36(12 \%)$ & $8(11.4 \%)$ & $28(12.2 \%)$ & 0.867 \\
\hline Diabetes mellitus & $155(51.7 \%)$ & $51(72.9 \%)$ & $104(45.2 \%)$ & $<0.001$ \\
\hline Duration of hypertension $>10$ years & $153(51 \%)$ & $52(74.3 \%)$ & $101(43.9 \%)$ & $<0.001$ \\
\hline Dyslipidaemia & $173(57.7 \%)$ & $45(64.3 \%)$ & $128(55.7 \%)$ & 0.201 \\
\hline Ischemic heart disease & $145(48.3 \%)$ & $42(60 \%)$ & $103(44.8 \%)$ & 0.026 \\
\hline Chronic kidney disease & $36(12 \%)$ & $10(14.3 \%)$ & $26(11.3 \%)$ & 0.502 \\
\hline
\end{tabular}

\begin{tabular}{lccc}
$\begin{array}{l}\text { Table 2: Gender-wise distribution of resistant } \\
\text { hypertension, other cardio-vascular risk factors } \\
\text { and co-morbidities }\end{array}$ & Male & Female & P value \\
\hline Parameters & $41(24.8 \%)$ & $29(21.5 \%)$ & 0.493 \\
\hline Resistant hypertension & $75(45.5 \%)$ & $67(49.6 \%)$ & 0.471 \\
Age (>55 years) & $65(39.4 \%)$ & $58(43 \%)$ & 0.532 \\
Family history of CVD & $40(24.2 \%)$ & $37(27.4 \%)$ & 0.532 \\
High salt intake & $82(49.7 \%)$ & $71(52.6 \%)$ & 0.618 \\
Obesity (BMI>27.5 kg/m $\left.{ }^{2}\right)$ & $34(20.6 \%)$ & $9(6.7 \%)$ & 0.001 \\
Smoking & $33(20 \%)$ & $3(2.2 \%)$ & $<0.001$ \\
Alcohol consumption & $89(53.9 \%)$ & $66(48.9 \%)$ & 0.384 \\
Diabetes mellitus & $87(52.7 \%)$ & $66(48.9 \%)$ & 0.508 \\
Duration of hypertension & & & \\
$>10$ years & $101(61.2 \%)$ & $77(57 \%)$ & 0.464 \\
Dyslipidaemia & $76(46.1 \%)$ & $69(51.1 \%)$ & 0.384 \\
Ischemic heart disease & $21(12.7 \%)$ & $15(11.1 \%)$ & 0.668 \\
Chronic kidney disease & $21 \%$ \\
\hline
\end{tabular}

is recognized as the sixth most important risk factor contributing to the overall burden of disease worldwide. ${ }^{17}$

\begin{tabular}{|c|c|c|c|c|}
\hline \multirow[t]{2}{*}{ Parameters } & \multirow[t]{2}{*}{$\begin{array}{c}\text { Relative } \\
\text { risk (Odds) }\end{array}$} & \multicolumn{2}{|c|}{$\begin{array}{c}95 \% \\
\text { confidence } \\
\text { interval }\end{array}$} & \multirow[t]{2}{*}{$P$ value } \\
\hline & & $\begin{array}{l}\text { Upper } \\
\text { limit }\end{array}$ & $\begin{array}{l}\text { Lower } \\
\text { limit }\end{array}$ & \\
\hline Age (>55 years) & 5.446 & 2.935 & 10.104 & $<0.001$ \\
\hline Obesity $\left(\mathrm{BMI}>27.5 \mathrm{~kg} / \mathrm{m}^{2}\right)$ & 2.433 & 1.387 & 4.268 & 0.002 \\
\hline Diabetes mellitus & 3.252 & 1.808 & 5.851 & $<0.001$ \\
\hline $\begin{array}{l}\text { Duration of hypertension } \\
>10 \text { years }\end{array}$ & 3.690 & 2.033 & 6.696 & $<0.001$ \\
\hline Ischaemic heart disease & 1.850 & 1.073 & 3.187 & 0.026 \\
\hline
\end{tabular}

It is said that compared with year 2000, the number of adults with hypertension is predicted to increase by $60 \%$ to a total of 1.56 billion by year $2025 .{ }^{18}$ Furthermore, more than 1 billion adults and $10 \%$ of children are now classified as either overweight or obese. ${ }^{17}$ Studies have 
shown that the cardiovascular risks in those with obesity are not significantly increased unless hypertension is present. ${ }^{19}$ This observation emphasizes the role of hypertension as a mediator through which obesity may cause cardiovascular disease. Our results also demonstrate that obesity was a significant factor associated with resistant hypertension in risk analysis (see Table 3). Obesity is associated with more severe hypertension, a need for an increased number of medications and a decreased likelihood of achieving blood pressurecontrol. ${ }^{20}$ This epidemic of obesity and obesityrelated hypertension is paralleled by an alarming increase in the incidence of diabetes mellitus and chronic kidney disease.

We observed a statistically significant relationship between diabetes mellitus and resistant hypertension in risk analysis (see Table 3). Hypertension in diabetics interferes with the rate of development and progression of diabetic complications, which in turn aggravates the hypertensive disease. It appears to be universally accepted that the tight treatment regimens for hypertension in diabetics reduces cardiovascular risk and slows the rate of progression of diabetic complications such as diabetic nephropathy.

Hypertension is usually linked with renal disease and it is both a cause and a complication of hypertension. However in our study sample the number of hypertensives with renal disease was minimal, probably due to the fact that there are specialized clinic for patients with renal disease, while we conducted the study in a specialized 'Hypertension Clinic'.

There are several limitations that need to be kept in mind when drawing conclusions from the present study. The cross-sectional design of our study limits the inference of causality for the risk factors identified. Therefore, it is important to conduct prospective studies on resistant hypertension and look for causality. There was also incomplete documentation on drug-prescribing decisions and regarding the hospital admissions due to disease complications. It may have led to an underestimation of the control of disease and medication intensifications. In addition, lack of diagnostic laboratory tests may have led to under ascertainment of co-morbidities. Furthermore, it is said that the genetic factors and mental stress are important aetiological agents for resistant hypertension. However we did not evaluate the patients stress levels in the present study. In addition although risk factors such as Diabetes, Ischaemic Heart Disease and Chronic Kidney Disease were considered, their severity was not evaluated. ${ }^{21}$

\section{CONCLUSION}

A significant proportion of the hypertensive patients, nearly one fourth, were identified as having Resistant hypertension, which was significantly associated with the presence of older age, obesity, diabetes mellitus, longer duration of hypertension and co-morbidity like Ischemic Heart Disease as risk factors as compared to non-resistant hypertension. Large scale prospective studies are needed on resistant hypertension for its causality and better understanding.

\section{REFERENCES}

1. Chobanian AV, Bakris GL, Black HR, Cushman WC, Green LA, Izzo JL, et al. Seventh report of the joint national committee on prevention, detection, evaluation, and treatment of high blood pressure. Hypertension 2003; 42(6):1206-1252.

2. Sarafidis PA. Epidemiology of resistant hypertension. J Clin Hypertension 2011; 13(7):523-528.

3. Xin X, He J, Frontini MG, Ogden LG, Motsamai OI and Whelton PK. Effects of alcohol reduction on blood pressure: a metaanalysis of randomized controlled trials. Hypertension 2001; 38(5):1112-1117.

4. Weinberger $\mathrm{MH}$. Salt sensitivity of blood pressure in humans. Hypertension 1996; 27(3.2):481-490.

5. Miller $\mathrm{NH}$, Hill $\mathrm{M}$, Kottke $\mathrm{T}$ and Ockene IS. The multilevel compliance challenge: recommendations for a call to action. A statement for healthcare professionals. Circulation 1997; 95(4):1085-1090.

6. Balazovjech I and Hnilica P Jr. Compliance with antihypertensive treatment in consultation rooms for hypertensive patients. J Human Hypertension 1993; 7(6):581-583.

7. Gerber JC and Stewart DL. Prevention and control of hypertension and diabetes in an underserved population through community outreach and disease management: a plan of action. J Assoc Acad Minority Physicians 1998; 9(3):48-52.

8. Wienick RM, Zuvekas SH and Cohen JW. Racial and ethnic differences in access to and use of Health care services. Med Care Res Rev 2000; 57(Suppl 1):36-54.

9. Cabana MD, Rand CS, Powe NR, Wu AW, Wilson MH, Abboud PA, et al. Why don't physicians follow clinical practice guidelines? A framework for improvement. JAMA 1999; 282(15):1458-1465.

10. Cuspidi C, Macca G, Sampieri L, Michev I, Salerno M, Fusi $\mathrm{V}$, et al. High prevalence of cardiac and extra-cardiac target organ damage in refractory hypertension. J Hypertension 2001; 19(11):2063-2070.

11. Bansal SK, Saxena V, Kandpal SD, Gray WK, Walker RW and Goel D. The prevalence of hypertension and hypertension risk factors in a rural Indian community: A prospective door-to-door study. J Card Disease Res 2012; 3(2):117-123.

12. Kumar A. Correlation between anthropometric measurement, lipid profile, dietary vitamins, serum antioxidants, lipoprotein (a) and lipid peroxides in known cases of 345 elderly hypertensive South Asian aged 56-64 y- A hospital based study. Asian Pac J Trop Biomed 2014;4 Suppl(1):S189-S197.

13. Carretero $\mathrm{OA}$ and Oparil S. Essential hypertension. Part I: definition andetiology. Circulation 2000; 101(3):329-335.

14. Consultation WHOE: Appropriate body-mass index for Asian populationsand its implications for policy and intervention strategies. Lancet 2004;363(9403):157-163.

15. Parascandola M, Augustson $E$ and Rose A. Characteristics of current andrecent former smokers associated with the use of new potentialreduced-exposure tobacco products. J Soc Res Nicot Tobacco 2009;11(12):1431-1438. 
16. Freiberg MS, Cabral HJ, Heeren TC, Vasan RS and Curtis Ellison R. Third National Health and Nutrition Survey. Alcohol consumption and the prevalence of theMetabolic Syndrome in the US.: a cross-sectional analysis of data from the Third National Health and Nutrition Examination Survey. Diab Care 2004; 27(12):2954-2959.

17. Haslam DW and James WP. Obesity. Lancet 2005; 366(9492):1197-1209.

18. Kearney PM, Whelton M, Reynolds K, Muntner P, Whelton PK and $\mathrm{He} \mathrm{J}$. Global burden of hypertension: analysis of worldwide data. Lancet 2005; 365(9455):217-223.

19. Thomas F, Bean K, Pannier B, Oppert JM, Guize L and Benetos A. Cardiovascular mortality in overweight subjects: the key role of associated risk factors. Hypertension 2005; 46(4):654-659.

20. Calhoun DA, Jones D, Textor S, Goff DC, Murphy TP, Toto RD, et al. Resistant hypertension: diagnosis,evaluation, and treatment. a scientific statement from the AmericanHeart Association Professional Education Committee of the Council forHigh Blood Pressure Research. Hypertension 2008; 51(6):1403-1419.

21. Santulli G. Coronary heart disease risk factors and mortality. JAMA 2012;307(11):1137. author reply 1138.

22. Centers for Disease Control and Prevention. State-specific secondhand smoke exposure and current cigarette smoking among adults-United States, 2008. MMWR Morb Mortal Wkly Rep 2009;58:1232-1235.

\section{Authors Contribution:}

PKM, AKD, SP - Idea, Data Collection, Result analysis, Manuscript preparation; SKD, SK, AD, SND, AS - Data Collection, Manuscript Preparation; SD - Result Analysis.

Source of Support: Nil, Conflict of Interest: None declared. 